\title{
Atmospheric Simulations Using OGCM-Assimilation SST: Influence of the Wintertime Japan Sea on Monthly Precipitation
}

\author{
Masaru Yamamoto* and Naoki Hirose \\ Research Institute for Applied Mechanics, Kyushu University, Kasuga 816-8580, Japan
}

Received 30 August 2008, accepted 18 March 2009

\begin{abstract}
Temperature data for the Japan Sea obtained from ocean data assimilation modeling is applied to atmospheric simulations of monthly precipitation for January 2005. Because the volume of flow of the Tsushima Warm Current was large during the winter season, the sea surface temperature (SST) and coastal precipitation were higher in comparison with those in 2003. In order to evaluate influence of SST on monthly precipitation, we use surface temperatures of the Japan Sea in 2003 and 2005 for comparative simulations of precipitation for January 2005. The precipitation in experiment C (using cool SST data in 2003) is smaller than that in experiment W (using warm SST data in 2005) in a large part of the sea area, since the small evaporation results from the low SST over the upstream area of northwesterly winter monsoon. In the domain of 33.67 $-45.82^{\circ} \mathrm{N}$ and $125.89-142.9^{\circ} \mathrm{E}$, the averaged evaporation and precipitation in experiment $\mathrm{C}$ are $10 \%$ and $13 \%$ smaller than those in experiment W, respectively. About half of the difference between the precipitations observed for January 2003 and 2005 in a heavy snow area is equal to the difference between the two simulations. Our results show that the mesoscale SST difference between 2003 and 2005 is related to the local difference of monthly precipitation.
\end{abstract}

Key words: Precipitation, SST, Japan Sea, Mesoscale atmospheric model, Data assimilation

Citation: Yamamoto, M. and N. Hirose, 2010: Atmospheric simulations using OGCM-assimilation SST: Influence of the wintertime Japan Sea on monthly precipitation. Terr. Atmos. Ocean. Sci., 21, 113-122, doi: 10.3319/TAO.2009.03.18.03(IWNOP)

\section{INTRODUCTION}

Warm currents in open seas, such as the Gulf Stream and Kuroshio, influence the weather and climate of the troposphere (e.g., Minobe et al. 2008). Similarly, warm currents in marginal seas are also expected to influence the troposphere through the distribution of sea surface temperature (SST) (e.g., Hirose and Fukudome 2006; Takano et al. 2008). The Japan Sea is highly important for wintertime weather systems leading to heavy snow fall in Japan. The Tsushima Warm Current in the southern part of the sea supplies moisture and heat to wintertime monsoons blowing toward the Japan Islands. Recently, Hirose and Fukudome (2006) found that the inlet flow volume of the warm current into the Japan Sea largely controls coastal precipitation through the SST, based on the ship-borne Acoustic Doppler Current Profiler (ADCP) observations in the Tsushima Strait between the Korean Peninsula and Kyushu Island (around

\footnotetext{
* Corresponding author

E-mail:yamakatu@riam.kyushu-u.ac.jp
}

$\left.34^{\circ} \mathrm{N}, 128^{\circ} \mathrm{E}\right)$. The volume of autumn flow determines the wintertime surface temperature in the semi-enclosed ocean where mesoscale oceanic eddies exist near the subpolar front and coastal area (Morimoto and Yanagi 2001). The high-resolution SST structure resulting from mesoscale oceanic eddies could influence mesoscale meteorology. However, the relationship between the high-resolution SST and precipitation in the marginal sea area is not yet fully understood.

Cloud cover is problematic for high-resolution infrared observation over wintertime marginal seas. In addition, a low-frequency microwave imager with a wide IFOV (instantaneous field of view) cannot avoid inclusion of missing data near the coast because of the influence of the temperature of coastal land. Thus, an optimum spatial and temporal interpolation is used for the daily SST estimates in order to account for the missing data. However, this interpolation smoothes high-resolution SST structures, such as mesoscale oceanic eddies. Recently, surface temperatures in the Japan Sea are estimated using satellite measurements in an eddy- 
resolving ocean circulation model (e.g., Manda et al. 2005; Hirose et al. 2007). Yamamoto and Hirose $(2007,2008)$ used high-resolution SST data in an ocean general circulation model (OGCM) to simulate a developing extratropical cyclone and cold-air outbreak over the Japan Sea and reported that the difference between the assimilation and interpolation SSTs could not be neglected in their simulations.

Chen et al. (2001) investigated the effects of the Advanced Very High Resolution Radiometer SST on atmospheric forcing in the Japan Sea and demonstrated the significance of the high resolution SST in monthly weather simulations. Recently we have used the new SST product by combining satellite measurements into the Japan Sea model and have investigated the effects of the ocean data assimilation on monthly precipitation. In comparison with a high-resolution interpolation SST, the OGCM-assimilation SST improves the precipitation simulation. In particular, the persistent high-resolution SST structure resulting from mesoscale oceanic eddies impacts monthly precipitation estimates in comparative experiments using the optimuminterpolation and OGCM-assimilation SST products (Yamamoto and Hirose 2009).

The precipitation in the Japan Sea coastal area is determined by both northwesterly monsoon intensity as an atmospheric factor and the SST distribution as an oceanic factor, as was discussed in Hirose and Fukudome (2006). In the 04/05 (02/03) winter season, the surface temperature was high (low) in the semi-closed Japan Sea, since the flow volume of the Tsushima Warm Current was large (small). Also, the East Asia monsoon index defined by the December to February sea level pressures at Irkutsu $\left(53^{\circ} 16^{\prime} \mathrm{N}\right.$, $\left.104^{\circ} 21^{\prime} \mathrm{E}\right)$ and Nemuro $\left(43^{\circ} 20^{\prime} \mathrm{N}, 145^{\circ} 35^{\prime} \mathrm{E}\right)$ in the $04 / 05$ season, which indicates the intensity of the winter monsoon (e.g., Yasuda and Hanawa 1999), was approximately 1.5-times higher than in the 02/03 season. The December to February precipitation in the northern coastal area of the Japan Islands in the 04/05 season was $200 \mathrm{~mm}$ higher than that in the $02 / 03$ season. In this study, we consider the effect of cool and warm SSTs in the meteorological situation for January 2005, but do not consider the effect of monsoon intensity.

Differently from Yamamoto and Hirose (2009), who used the smoothed (interpolation) and eddy-resolving (assimilation) SSTs in January 2005, the Japan-Sea assimilation surface temperatures in January 2003 and 2005 are used as cool and warm SSTs in the present study, respectively. Since the meteorological impact of the existence or absence of oceanic mesoscale eddies has been already discussed in Yamamoto and Hirose (2009), we focus on the influence of the eddy-resolving cool and warm SSTs on the precipitation in the meteorological situation for January 2005. The detailed numerical method is described in section 2 . The influence of the SST difference on the precipitation is investigated in section 3 and we discuss the relationship between the SST and precipitation in the marginal sea area. Finally, the results are summarized in section 4 .

\section{DATA AND MODEL}

We examine the influence of SST on monthly atmospheric simulations over the Japan Sea in January 2005. For the semi-enclosed Japan Sea area, the OGCM-assimilation SST in 2005 is used for experiment W, and SST in 2003 for experiment $\mathrm{C}$. The SST in experiment $\mathrm{W}$ (experiment C) is high (low), since the inlet flow volume through the Tsushima Strait is large (small). The SST data with a $1 / 12^{\circ}$ resolution in latitude/longitude is obtained by combining satellite measurements (sea surface temperature and height) and ADCP observations (inlet flow volume through the Tsushima Strait) into an ocean circulation model of the Research Institute for Applied Mechanics (RIAM), Kyushu University, Japan. This assimilation product, which is estimated by nudging with a relaxation time of 3 days for SST and by an approximation using the Kalman filter procedure for the sea surface height (SSH) (Hirose et al. 2007), provides a daily high-resolution SST data for the cloudy Japan Sea area and is consistent with the mesoscale oceanic eddies detected from the satellite altimeter observation.

We used the PSU/NCAR mesoscale model (MM5 version 3) (Dudhia 1993; Grell et al. 1995; Dudhia et al. 2005) with 23 sigma layers (divided by $\sigma=1.00,0.99,0.98,0.96$, $0.93,0.89,0.85,0.80,0.75,0.70,0.65,0.60,0.55,0.50$, $0.45,0.40,0.35,0.30,0.25,0.20,0.15,0.10,0.05,0.00$ ). The initial (0000 UTC 31 December 2004) and boundary conditions are calculated from NCEP Global Tropospheric Analyses (ds083.2) and NCEP ADP Global Upper Air Observation Subsets (ds353.4). The outer domain (domain 1) with a central latitude of $35^{\circ} \mathrm{N}$ and longitude of $135^{\circ} \mathrm{E}$ has a $103 \times 121$ horizontal grid with $30 \mathrm{~km}$ resolution (Fig. 1a), and the two-way nested domain (domain 2) with $10 \mathrm{~km}$ resolution $(130 \times 130$ grid $)$ is located in the Japan Sea (Fig. 1b). SSTs in 2003 and 2005 are given each day for the area between $32.96-53.12^{\circ} \mathrm{N}$ and $126.46-142.46^{\circ} \mathrm{E}$ for experiment $\mathrm{C}$ and experiment $\mathrm{W}$, respectively, and weekly NOAA optimum interpolation SST (Reynolds and Smith 1994) is used in other areas for both experiments. Atmospheric radiation is calculated by choosing the cloud-radiation option and a 5-layer soil model based on the vertical diffusion equation is used for the calculation of the land-surface temperature. An explicit moisture scheme including mixed phase, the Medium-Range Forecast Planetary Boundary Layer (MRF-PBL) scheme, and Grell cumulus parameterization (useful for 10 - $30 \mathrm{~km}$ resolutions) are applied to the simulation (Dudhia et al. 2005). The sensible and latent heat fluxes are calculated by bulk-aerodynamics parameterization (e.g., Deardorff 1972; Grell et al. 1995).

The 3D grid nudging is applied to the atmosphere in the outer domain. The wind and temperature are correct- 
(a)

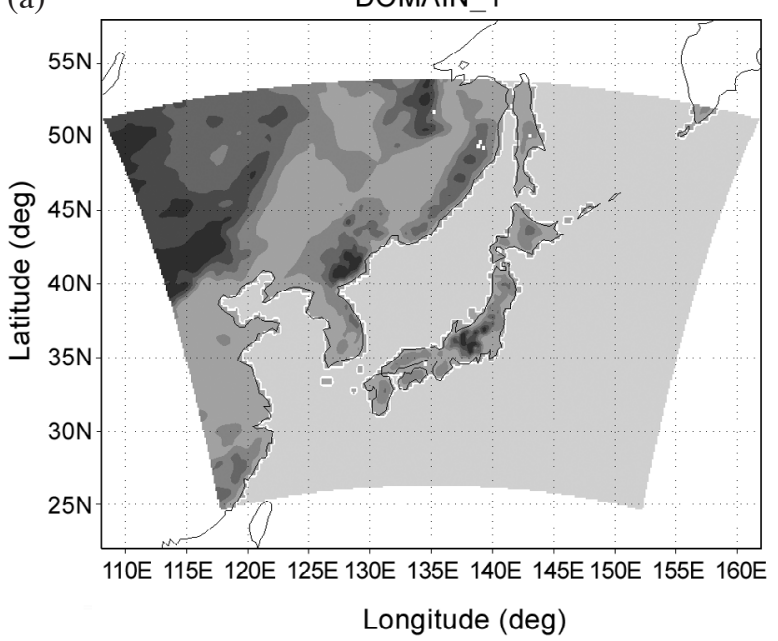

(b)

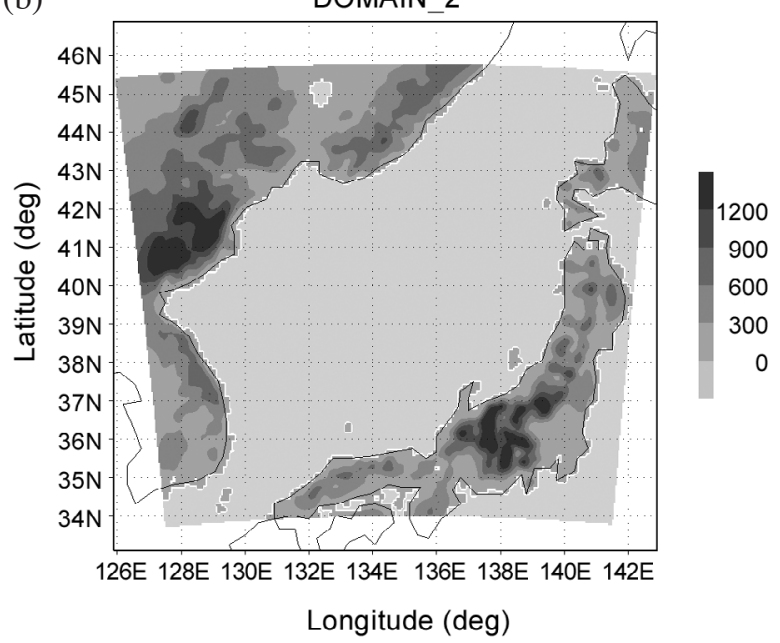

Fig. 1. Horizontal distributions of model domains (gray shading) and elevations (m) of (a) domain 1 and (b) domain 2.

ed every 6 hours by nudging using a coefficient of $2.5 \times$ $10^{-4} \mathrm{~s}^{-1}$, and a mixing ratio of $1.0 \times 10^{-5} \mathrm{~s}^{-1}$. The reference data of the wind, temperature, and mixing ratio, which are used for the 3D grid nudging, are calculated from the NCEP Global Tropospheric Analyses and NCEP ADP Global Upper Air Observation Subsets. Since the realistic reference data are used for the 3D grid nudging and initial condition, the spin up time is set at $24 \mathrm{~h}$ in the same way as the regional mesoscale simulations using the same domains (Yamamoto and Hirose 2007, 2008). Thus, the simulation is started from 0000 UTC 31 December 2004. According to Yamamoto and Hirose (2009), the monthly precipitation for January 2005 is insensitive to the initial conditions altered from December 25 to January 1 in the nudging simulations, since the nudging prevents the chaotic error growth in the outer domain and the two-way nested inner domain. In the present study, under the appropriately nudged atmospheric condition in the outer domain, we investigate the influence of cool and warm SSTs on the monthly precipitation in the inner Japan Sea domain for January.

In the present simulation, we modify the model setup of Yamamoto and Hirose (2009) (in which $2.5^{\circ} \times 2.5^{\circ}$ data of ds083.0 and an explicit moisture scheme including simple ice were used) using the NCEP Global Tropospheric Analyses $\left(1.0^{\circ} \times 1.0^{\circ}\right.$ resolution data, ds083.2) and the microphysics option (an explicit moisture scheme including a mixed phase). As a result, the root mean squared error of the model (112 $\mathrm{mm}$ in experiment $\mathrm{W})$ is improved in the Japanese heavy snow fall area (Fig. 10a), compared with the results from Yamamoto and Hirose (2009) (121 mm).

\section{RESULTS}

Figures 2a and $b$ show monthly mean SSTs used in experiments $\mathrm{W}$ and $\mathrm{C}$, respectively. Warm-temperature water transported by the Tsushima Warm Current in experiment $\mathrm{W}$ (contours of 12 and $14^{\circ} \mathrm{C}$ in Fig. 2a) extends eastward along the coast of the Japan Islands and northward along the Korean Peninsula. Since the inlet flow volume of the warm current in the 2005 autumn/winter season is larger than that in 2003, the SST in experiment W is higher than that in experiment $\mathrm{C}$ over large parts of the Japan Sea area, as shown in Fig. 2c. As will be noted, the significant differences between the two sets of the SSTs influence the monthly water cycle in mesoscale atmospheric simulations.

To begin with, the overall influences of SST on the regional weather system are discussed by statistical differences. The area averages over a domain of $33.67-45.82^{\circ} \mathrm{N}$ and $125.89-142.9^{\circ} \mathrm{E}$ are listed in Table 1 . The area-averaged surface temperature in experiment $\mathrm{C}$ is $0.76^{\circ} \mathrm{C}$ smaller than that in experiment $\mathrm{W}$. This difference mostly results from the surface temperature of the Japan Sea. The precipitable water $P W A T(\mathrm{~mm})$ and surface wind magnitude $U 10\left(\mathrm{~m} \mathrm{~s}^{-1}\right)$ in experiment $\mathrm{C}$ are $3.4 \%$ and $2.1 \%$ smaller than those in experiment $\mathrm{W}$, respectively. The vertically integrated cloud water $I C L W(\mathrm{~mm})$ in experiment $\mathrm{W}$ is $12 \%$ higher than that in experiment $\mathrm{C}$.

Large decreases in evaporation and precipitation caused by the low SST are predicted for the Japan-Sea domain. The area-averaged evaporations are 184 and $166 \mathrm{~mm}$ in experiments $\mathrm{W}$ and $\mathrm{C}$, respectively. The mean precipitation $(100 \mathrm{~mm})$ in experiment $\mathrm{W}$ represents $54 \%$ of the evaporation, and the precipitation $(87 \mathrm{~mm})$ in experiment $\mathrm{C}$ is $52 \%$. In the atmosphere where horizontal wind and air temperature in experiment $\mathrm{W}$ are similar to those in experiment $\mathrm{C}$ due to $3 \mathrm{D}$ grid nudging, the ratios of mean precipitation to evaporation are almost the same in the two experiments. About half of the total evaporation is transformed to the precipitation around the Japan Islands, while the remaining half is transported toward the outer regions. The monthly evapo- 

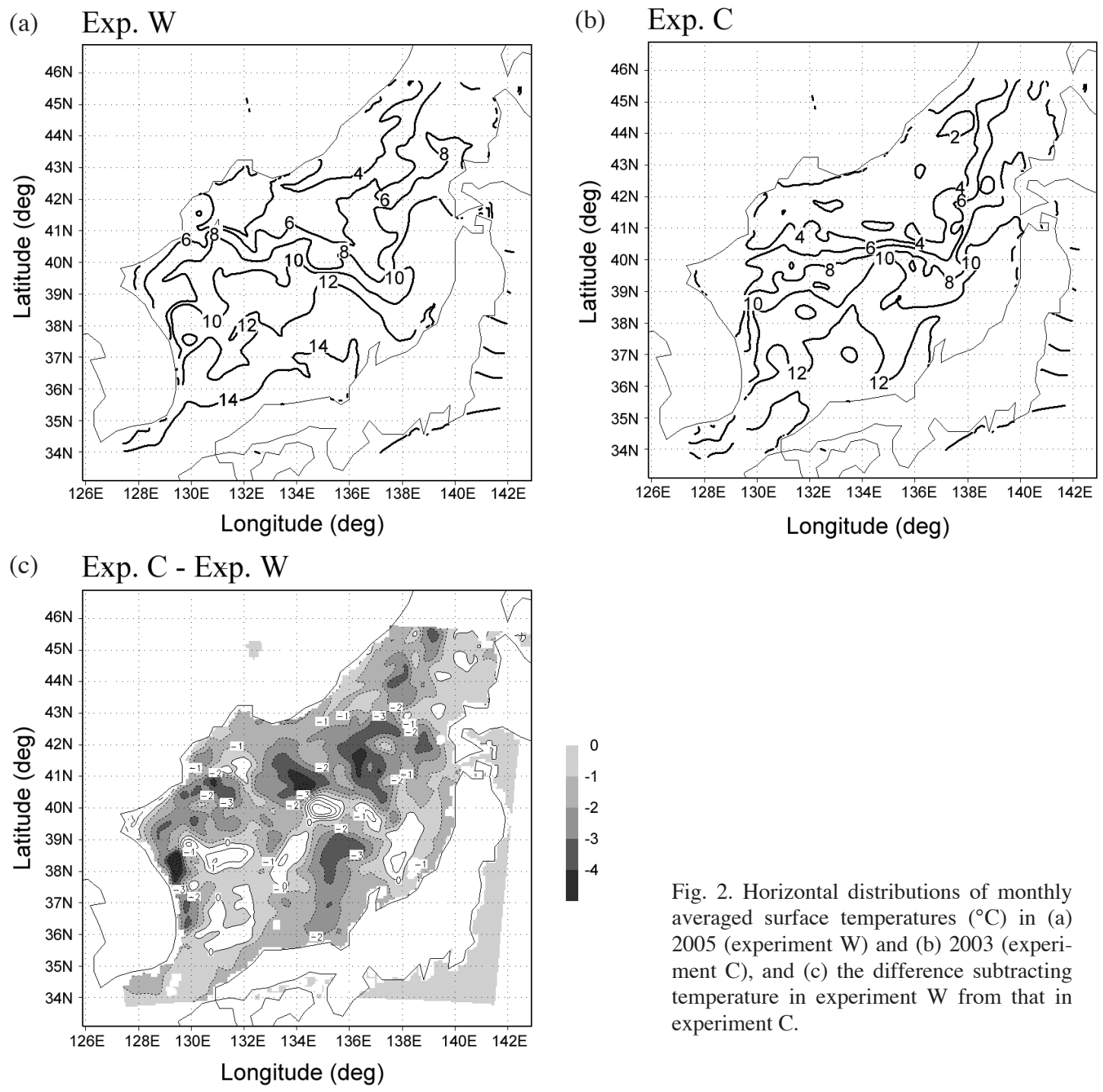

Fig. 2. Horizontal distributions of monthly averaged surface temperatures $\left({ }^{\circ} \mathrm{C}\right)$ in (a) 2005 (experiment W) and (b) 2003 (experiment $\mathrm{C}$ ), and (c) the difference subtracting temperature in experiment $\mathrm{W}$ from that in experiment $\mathrm{C}$.

Table 1. Averages over the Japan-Sea domain in experiments $\mathrm{W}$ and $\mathrm{C}$.

\begin{tabular}{lcccccc}
\hline Experiment & $\boldsymbol{T}_{\boldsymbol{g}}\left({ }^{\circ} \mathbf{C}\right)$ & $\boldsymbol{E}(\mathbf{m m})$ & $\boldsymbol{P}(\mathbf{m m})$ & $\boldsymbol{I C L W}(\mathbf{m m})$ & $\boldsymbol{P W A T}(\mathbf{m m})$ & $\boldsymbol{U} \boldsymbol{1 0}\left(\mathbf{m ~ s}^{-1}\right)$ \\
\hline C & 2.56 & 166 & 87 & $1.77 \times 10^{-2}$ & 6.21 & 5.92 \\
W & 3.32 & 184 & 100 & $2.02 \times 10^{-2}$ & 6.43 & 6.05 \\
C-W & -0.76 & -18 & -13 & $-0.25 \times 10^{-2}$ & -0.22 & -0.13 \\
\hline
\end{tabular}

Note: $T_{g}, E, P, I C L W, P W A T$, and U10 indicate the surface temperature, evaporation, precipitation, vertically-integrated cloud water, vertically-integrated water vapor (precipitable water), and the horizontal wind magnitude at the 10-m level above the surface, respectively.

ration $E$ and precipitation $P$ in experiment $\mathrm{C}$ are $10 \%$ and $13 \%$ smaller than those in experiment $\mathrm{W}$, respectively. The evaporation decrease of $18 \mathrm{~mm}$ in experiment $\mathrm{C}$ in comparison with experiment $\mathrm{W}$ causes a precipitation decrease of $13 \mathrm{~mm}$. Thus, the difference of evaporation due the SST variation influences the precipitation over the Japan Sea domain. The net evaporation $(E-P)$ in experiment $\mathrm{W}(84 \mathrm{~mm})$ is almost the same as or somewhat greater than that in experiment $\mathrm{C}(79 \mathrm{~mm})$.

Figure 3 shows simulated monthly mean surface heat fluxes (which equal the summation of the surface turbulent sensible and latent heat fluxes) and horizontal winds. Although the surface winds are almost the same in the two simulations, we can find a large difference in the surface 
(a)

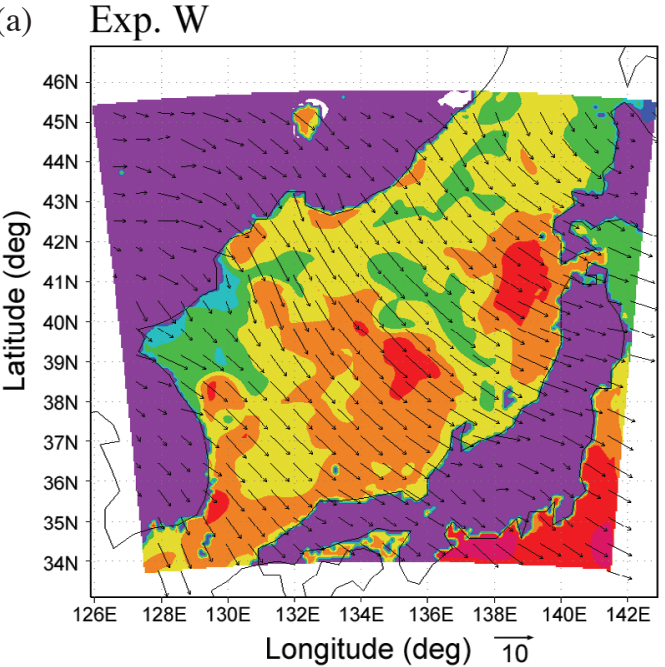

(c) Exp. C - Exp. W

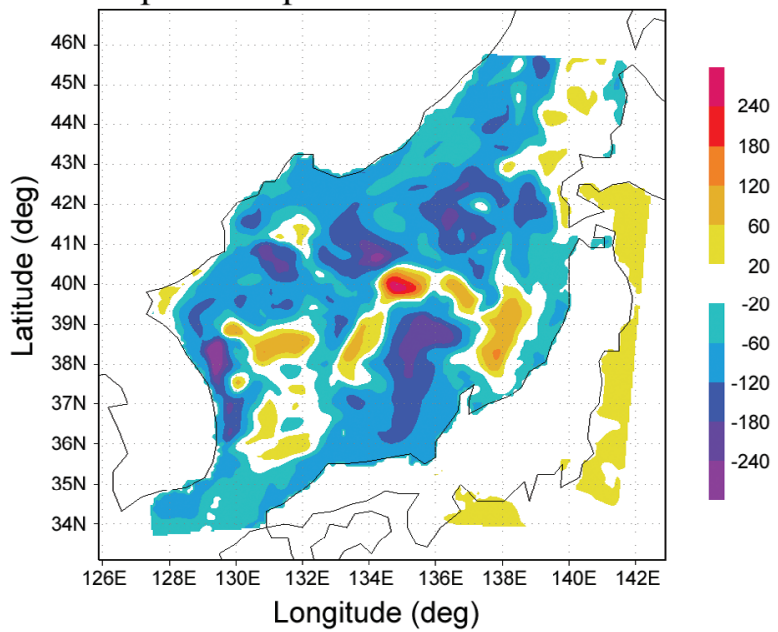

(b)

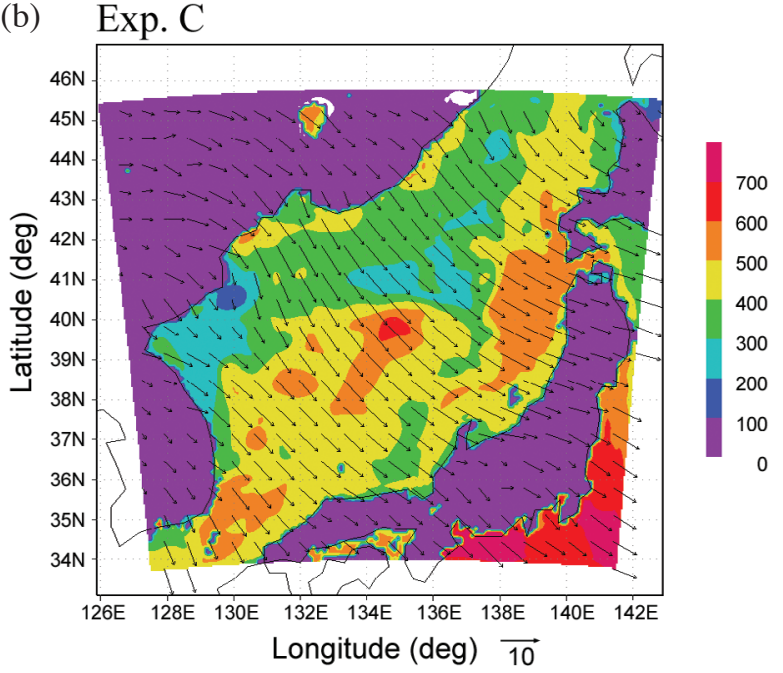

Fig. 3. Horizontal distributions of monthly averaged surface turbulent heat flux $\left(\mathrm{W} \mathrm{m}^{-2}\right)$ and horizontal wind $\left(\mathrm{m} \mathrm{s}^{-1}\right)$ in (a) experiment $\mathrm{W}$ and (b) experiment $\mathrm{C}$, and (c) the difference subtracting the flux in experiment $\mathrm{W}$ from that in experiment $C$. heat flux distributions in experiments $\mathrm{W}$ and $\mathrm{C}$. This means that the heat flux difference can be attributed to the SST, rather than surface wind. Large heat fluxes of more than $600 \mathrm{~W} \mathrm{~m}^{-2}$ are observed near $38.5^{\circ} \mathrm{N}, 135.5^{\circ} \mathrm{E}$ and $41.0^{\circ} \mathrm{N}$, $139.9^{\circ} \mathrm{E}$ in experiment W (Fig. 3a), and small heat flux is located on the southeast-directed cold SST tongue around $40^{\circ} \mathrm{N}, 137^{\circ} \mathrm{E}$. In most of the sea area, a rich supply of heat is found in experiment $\mathrm{W}$ compared to experiment $\mathrm{C}$. The distribution of the heat flux difference is remarkably similar to that of the SST difference (2003's SST - 2005's SST in Fig. 2c). The decrease of $3^{\circ} \mathrm{C}$ in SST leads to that of about $200 \mathrm{~W} \mathrm{~m}^{-2}$ near $38^{\circ} \mathrm{N}, 135^{\circ} \mathrm{E}$.

Monthly mean surface sensible fluxes, latent heat fluxes, and the Bowen ratios are shown in Figs. 4 - 6. The Bowen ratio is defined by the ratio of the sensible surface flux to the latent flux. The mesoscale distributions of the heat fluxes with horizontal scales of $\sim 200 \mathrm{~km}$ are evident, but differ between the two cases. In the cold SST tongue at $39^{\circ} \mathrm{N}, 137^{\circ} \mathrm{E}$, the sensible surface and latent heat fluxes are small along the northwesterly flow in experiment $\mathrm{W}$. On the other hand, the low-flux tongues are not seen in experiment C. The sensible heat flux is high in the upstream area of the northwesterly monsoons (the coast of the Eurasia Continent), while the latent heat flux is high in the downstream area (the coasts of the Japan Islands). The Bowen ratios are 1.5 and 0.7 in upstream and downstream areas, respectively (Fig. 6). In the coastal area of $40^{\circ} \mathrm{N}, 139^{\circ} \mathrm{E}$, both the sensible and latent fluxes are large for the two cases, and thus the Bowen ratio is unity. In contrast to the mesoscale distributions of the heat fluxes, there are no eddy structures and only a small difference between the two cases for the Bowen ratio. Figure 7 shows the differences between experiments $\mathrm{W}$ and $\mathrm{C}$ in the sensible and latent heat fluxes. The distributions of these differences are also remarkably similar to that of the SST difference (Fig. 2c). The SST decrease of $3^{\circ} \mathrm{C}$ near $38^{\circ} \mathrm{N}, 135^{\circ} \mathrm{E}$ leads to a decrease of about 90 and $120 \mathrm{~W} \mathrm{~m}^{-2}$ for the sensible heat and latent heat fluxes, respectively.

Vertically integrated water vapor and cloud water become larger as approaching the Japan Islands, as shown in Fig. 8. We can see the southeast-directed area of low cloud 

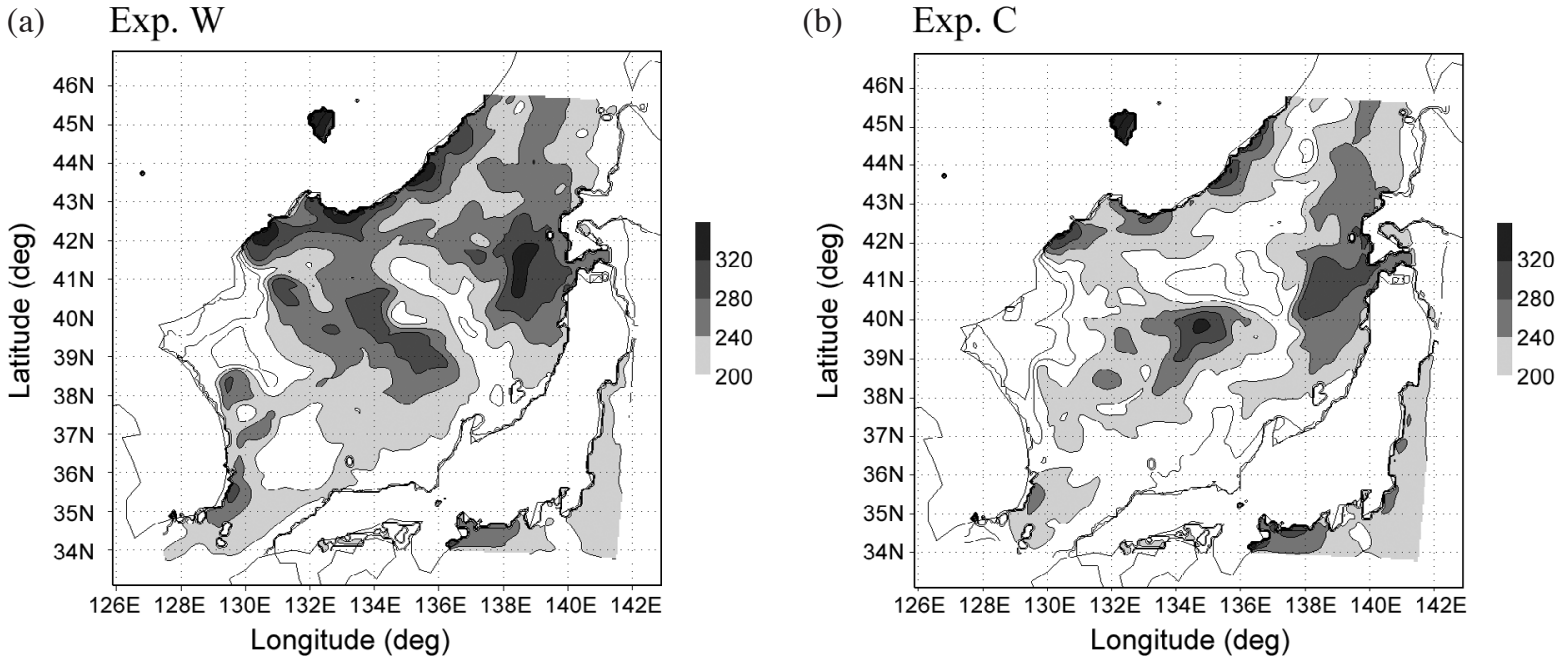

Fig. 4. Horizontal distributions of monthly averaged surface sensible heat fluxes in (a) experiment $\mathrm{W}$ and (b) experiment $\mathrm{C}$.

(a) Exp. W

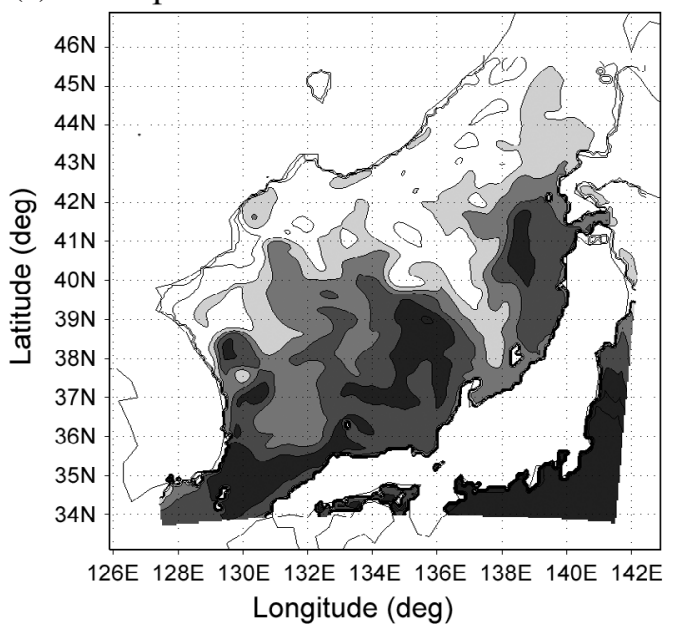

(b) Exp. C

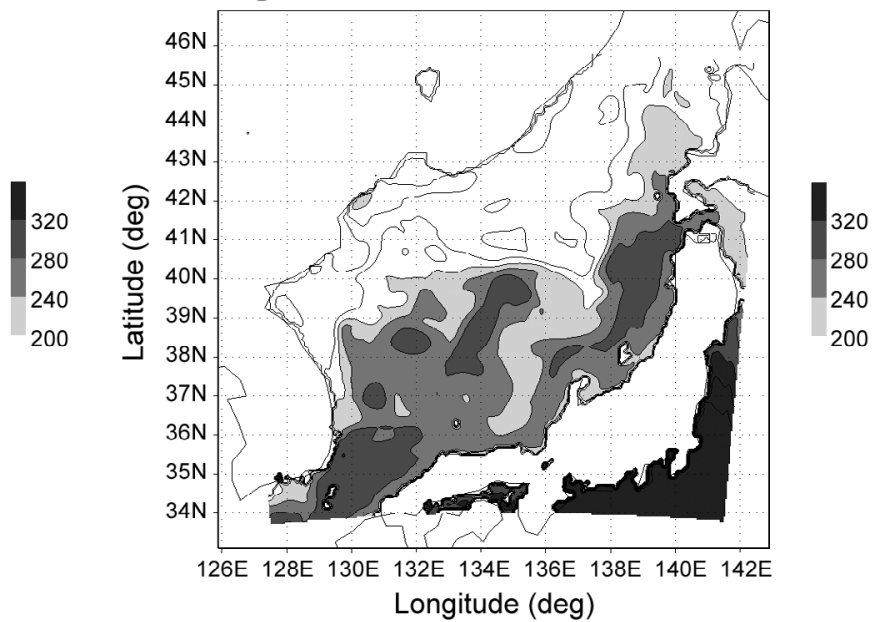

Fig. 5. Horizontal distributions of monthly averaged surface latent heat fluxes in (a) experiment W and (b) experiment C.

(a) Exp. $\mathrm{W}$

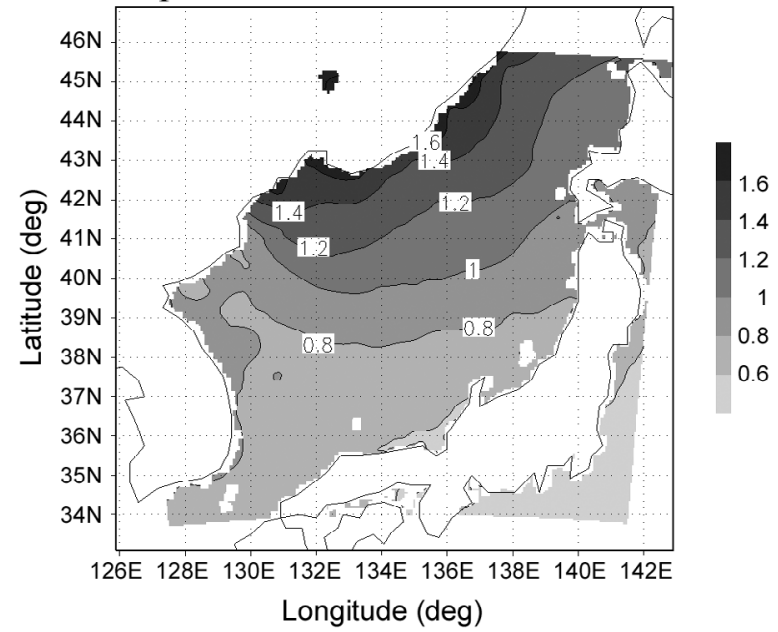

(b)

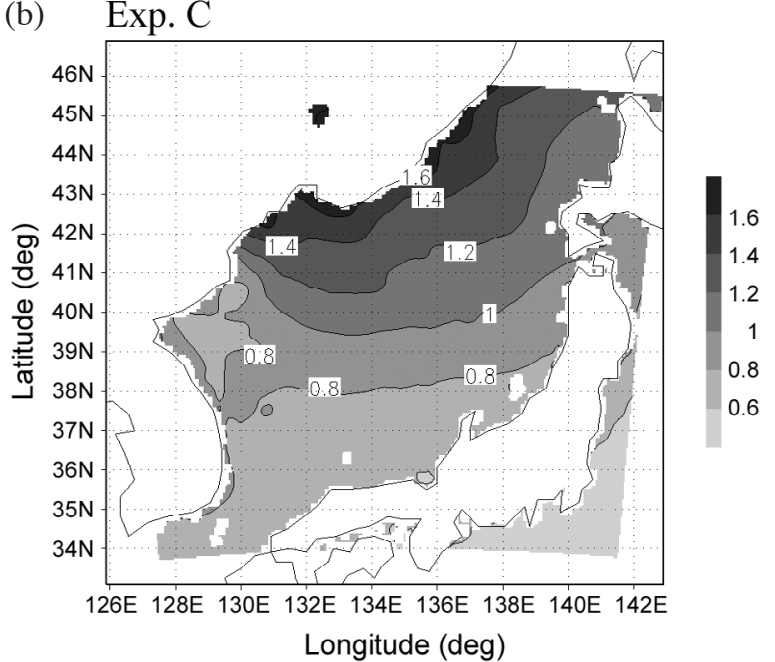

Fig. 6. Horizontal distributions of the monthly averaged Bowen ratios in (a) experiment $\mathrm{W}$ and (b) experiment $\mathrm{C}$. 
(a) Exp. C - Exp. W

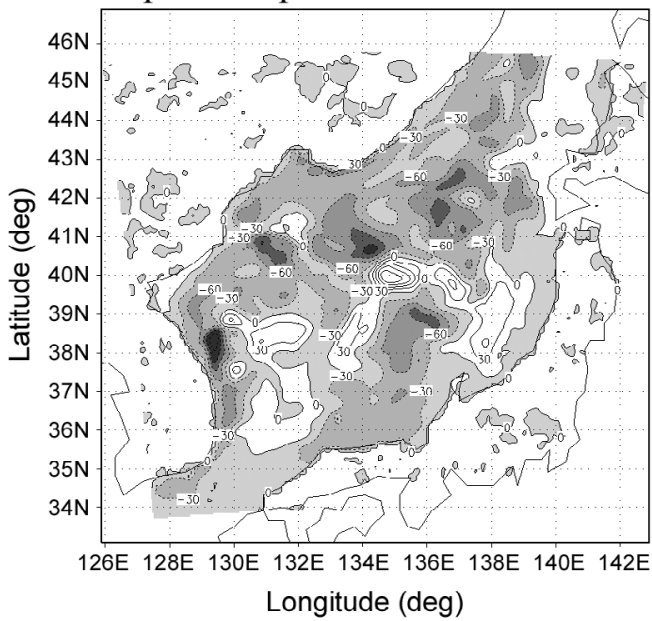

(b) Exp. C - Exp. W

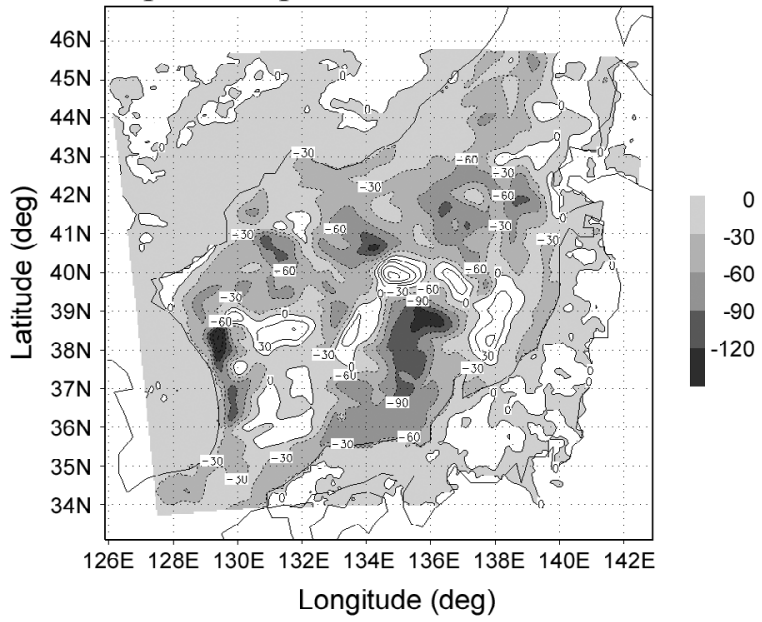

Fig. 7. Horizontal distributions of the differences between experiments $\mathrm{W}$ and $\mathrm{C}$ in monthly averaged surface (a) sensible heat flux and (b) latent heat flux $\left(\mathrm{W} \mathrm{m}^{-2}\right)$, subtracting those in experiment $\mathrm{W}$ from experiment $\mathrm{C}$.
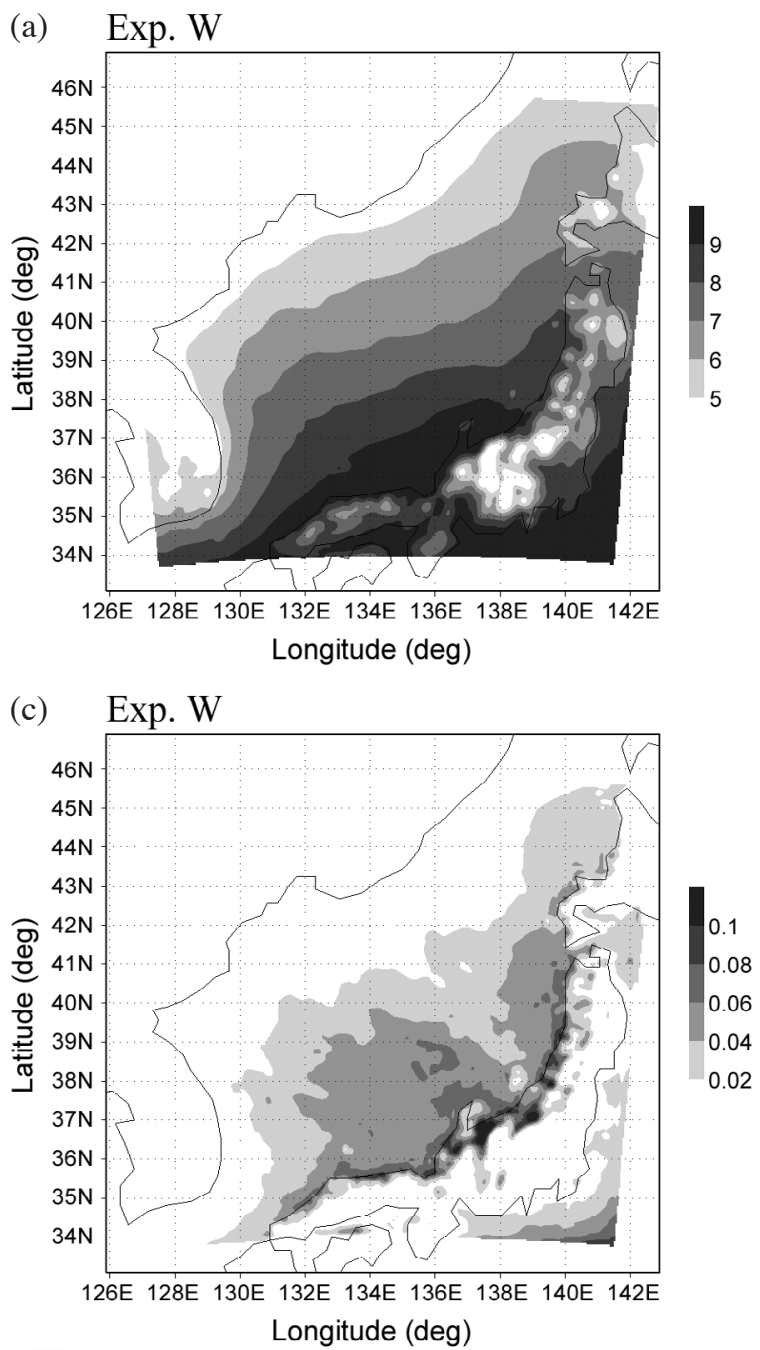
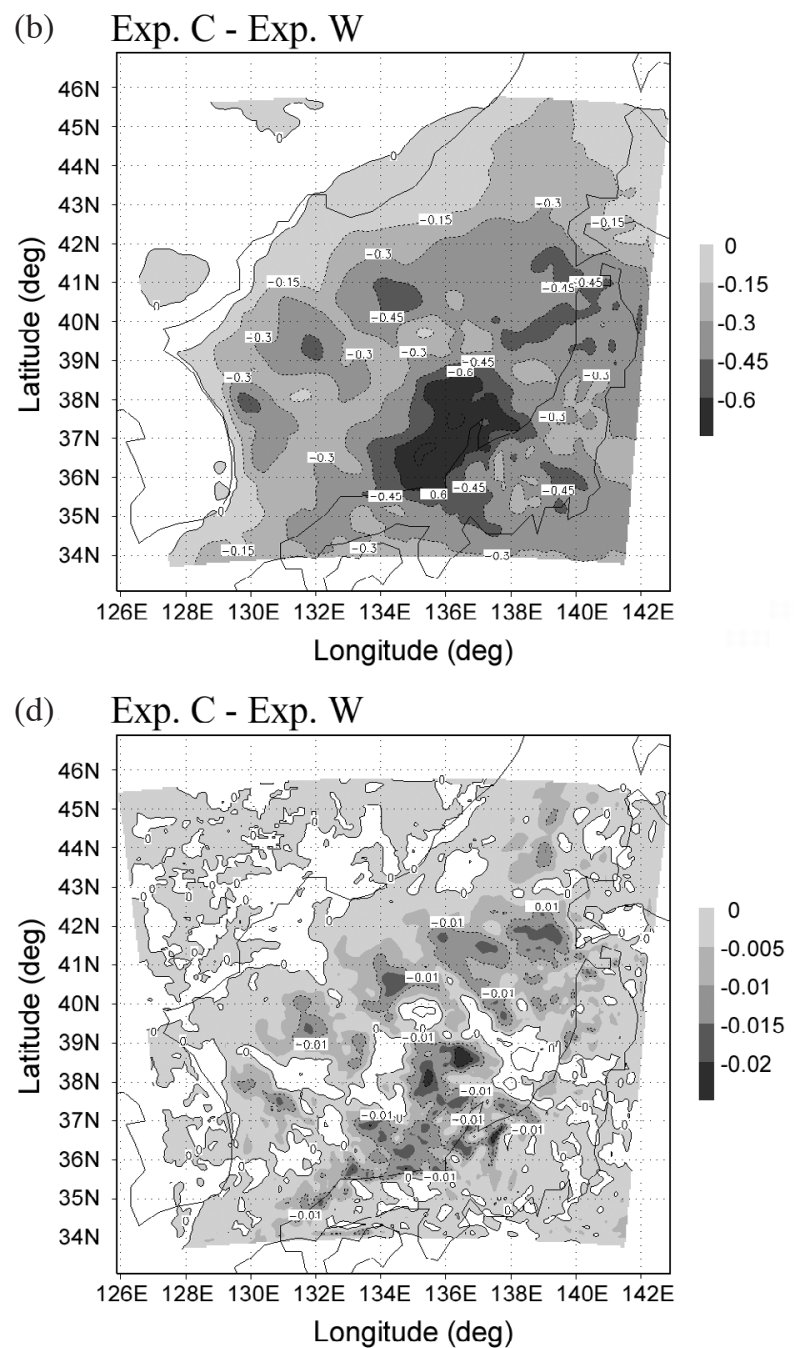

Fig. 8. Horizontal distributions of (a) monthly mean vertically-integrated water vapor (precipitable water, mm) in experiment $\mathrm{W}$ and (b) the difference subtracting that in experiment $\mathrm{C}$ from experiment $\mathrm{W}$ and of (c) monthly mean vertically-integrated cloud water ( $\mathrm{mm}$ ) in experiment $\mathrm{W}$ and (d) the difference subtracting that in experiment $\mathrm{C}$ from experiment $\mathrm{W}$. 
water along the cold SST tongue, but not for vertically integrated water vapor. In the negative SST difference area where SST in experiment $\mathrm{C}$ is $3^{\circ} \mathrm{C}$ lower than SST in experiment $\mathrm{W}$ near $38^{\circ} \mathrm{N}, 135^{\circ} \mathrm{E}$, vertically integrated water vapor and cloud water decrease by 0.6 and $0.01 \mathrm{~mm}$, respectively. Near the positive SST difference area where SST in experiment $\mathrm{C}$ is higher than SST in experiment $\mathrm{W}$, the differences in the two experiments have small negative values for the water vapor and large positive values for the cloud water.

Figure 9a shows monthly evaporation from the Japan Sea. High evaporation of $>300 \mathrm{~mm}$ is found near the coastal area of the Japan Islands where SST is high because of the Tsushima Warm Current. The water vapor supply is smaller over the southeast-directed cold SST tongue around $40^{\circ} \mathrm{N}$, $137^{\circ} \mathrm{E}$. As a whole, the evaporation from the sea in experiment $\mathrm{W}$ is larger than that in experiment $\mathrm{C}$ (Fig. 9b). A significant decrease of $>120 \mathrm{~mm}$ in evaporation is observed near $38^{\circ} \mathrm{N}, 135^{\circ} \mathrm{E}$, where $\mathrm{SST}$ for 2003 is $3^{\circ} \mathrm{C}$ lower than SST for 2005, and the local increases of evaporation (0 $120 \mathrm{~mm}$ ) are located in this area. The difference in mesoscale oceanic eddies leads to that in evaporation over the Japan Sea. Thus, the mesoscale ocean process appears to influence the moisture supply from the sea.

Figures $9 \mathrm{c}$ and $\mathrm{d}$ show monthly precipitation in experiment $\mathrm{W}$ and the difference between the two experiments, respectively. Heavy precipitation is found along the Japan Sea side of the Japan Islands. The precipitation in experiment $\mathrm{C}$ is smaller than that in experiment $\mathrm{W}$ in a large part of the sea area, except for $38.5^{\circ} \mathrm{N}, 139.5^{\circ} \mathrm{E}$. The decrease of the precipitation is caused by the decrease of the evaporation resulting from low SST over the upstream area of northwesterly wind. Noted that the low SST is likely caused by the small inlet flow of the Tsushima Warm Current during the autumn (Hirose and Fukudome 2006). A local increase in precipitation is found in the coastal area near $38.5^{\circ} \mathrm{N}, 139.5^{\circ} \mathrm{E}$, because of an increase in evaporation of $>30 \mathrm{~mm}$ due to mesoscale oceanic eddies in the upstream coastal area. The mesoscale difference in SST leads to the local difference of monthly precipitation. In particular, the precipitation difference of $>90 \mathrm{~mm}$ is found in the coastal areas of the Japan Islands, where the influence by the upstream oceanic frontal eddies can occur. This implies that the monthly forecast of mesoscale oceanic eddies is essential in forecasting local precipitation.

Finally, we discuss the influence of SST on the precipitation in heavy snow fall areas. In order to quantitatively evaluate the SST effect, we compare the model results with in-situ observation by hyetometer at the 175 AMeDAS (Automated Meteorological Data Acquisition System) sites (Fig. 10a). The scatter plot of the simulated and observed monthly precipitations is shown in Fig. 10b. Although the modeled monthly precipitation is larger than the observation for many sites, the agreement is better for experiment $\mathrm{W}$. Figure 10c shows the scatter plot of the monthly precipi- tations simulated in experiments $\mathrm{W}$ and $\mathrm{C}$ in order to elucidate the impact of the SST on the precipitation. The monthly precipitation amounts of less than $500 \mathrm{~mm}$ in experiment $\mathrm{W}$ are $0-30 \%$ smaller than those in experiment C (using low SST in 2003) in most sites. For precipitation amounts greater than $500 \mathrm{~mm}$, the differences between experiments $\mathrm{W}$ and $\mathrm{C}$ are small within $0-15 \%$. The impact of SST on low precipitation amounts $(<500 \mathrm{~mm})$ is large in comparison with that for larger precipitation amounts of $>500 \mathrm{~mm}$. The low monthly precipitation in the heavy snow fall area are sensitive to the SST variation in the Japan Sea. The simulated precipitations averaged over the observation sites are 355.0 and $312.5 \mathrm{~mm}$ in experiments $\mathrm{W}$ and C, respectively. The decrease of SST in experiment C leads to a $42.5 \mathrm{~mm}$ decrease in precipitation, which is $51 \%$ of the observed difference between those in 2003 and $2005(83.7 \mathrm{~mm})$.

\section{CONCLUDING REMARKS}

In this study, we investigate the influence of SST on monthly precipitation for January 2005 . The flow volume of the Tsushima Warm Current was large in this season, and the Japan Sea surface temperature and coastal precipitation were high in comparison with those in 2003 when the flow volume of the inlet warm current was smaller. In order to evaluate the influence of SST on monthly precipitation, we use the assimilation data of the Japan Sea surface temperatures in 2003 (experiment C) and 2005 (experiment W) in comparative experiments of precipitation for January 2005.

Rich supplies of heat and moisture are found in experiment $\mathrm{W}$ compared to experiment $\mathrm{C}$. The precipitation in experiment $\mathrm{W}$ is larger than that in experiment $\mathrm{C}$ in most of the sea area, except for $38.5^{\circ} \mathrm{N}, 139.5^{\circ} \mathrm{E}$. The increase in precipitation is caused by the increase of the evaporation resulting from high SST over the upstream area of northwesterly wind. The monthly precipitation is equal to about half of the evaporation over the domain of $33.67-45.82^{\circ} \mathrm{N}$ and $125.89-142.9^{\circ} \mathrm{E}$. The difference between the two SSTs largely influences the evaporation and precipitation. The modeled evaporation and precipitation are $10 \%$ and $13 \%$ larger than those in experiment $\mathrm{C}$ using the low SST in 2003, respectively.

The mesoscale difference in SST due to the year-toyear oceanic variation leads to local differences of monthly precipitation. In most of the heavy snow fall area, the monthly precipitation in experiment $\mathrm{C}$ is smaller than that in experiment $\mathrm{W}$. The decrease of SST in experiment $\mathrm{C}$ leads to the $42.5-\mathrm{mm}$ decrease of the simulated precipitation, which is $51 \%$ of the observational difference between those in 2003 and 2005 (83.7 mm).

The autumn/winter large (small) inlet flow volume of the Tsushima Warm Current through the Tsushima Strait results in higher (lower) Japan-Sea surface temperatures for 2005 (2003). In addition, the year-to-year variation of 
(a) Exp. W

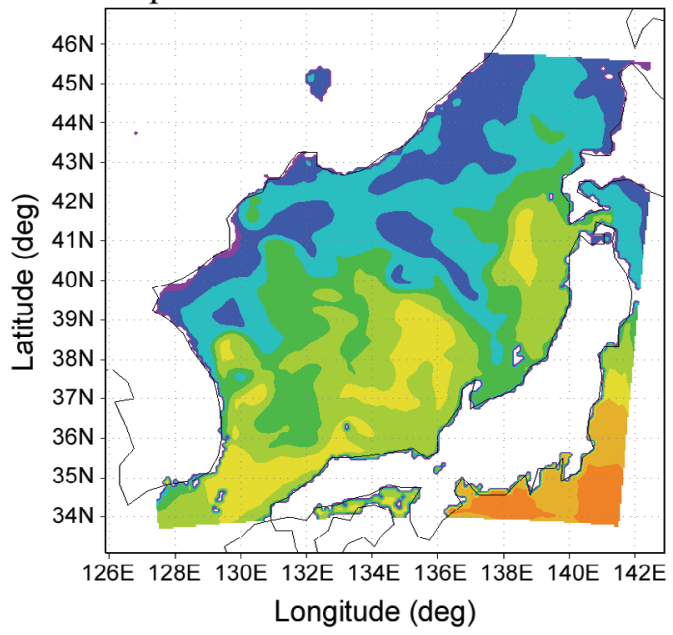

(c) Exp. W

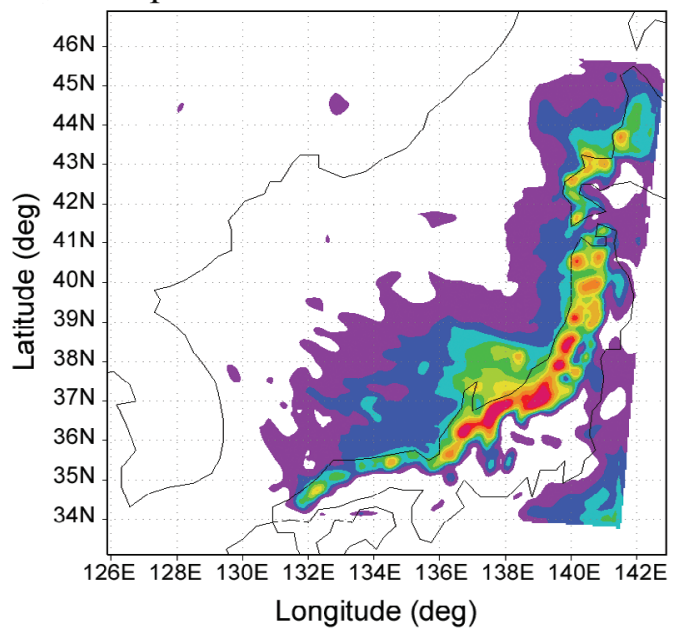

(b) Exp. C - Exp. W

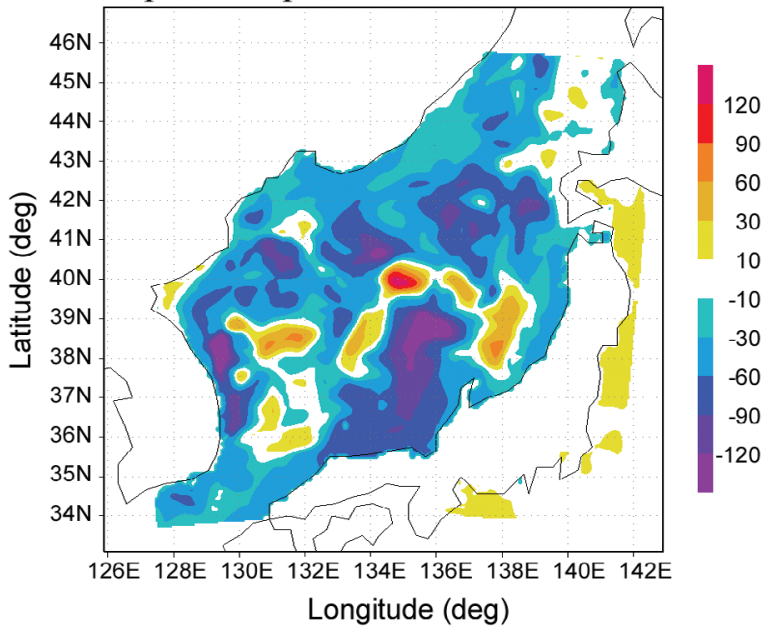

(d) Exp. C - Exp. W

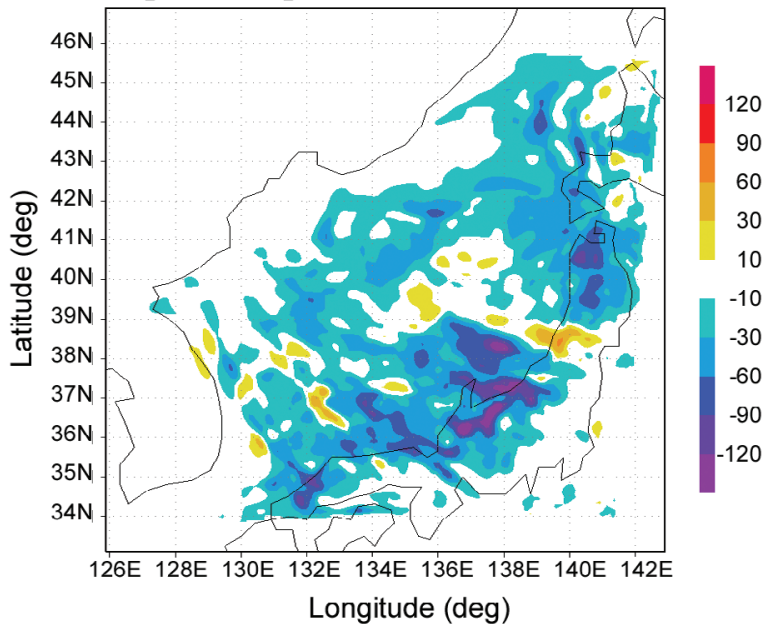

Fig. 9. Horizontal distributions of (a) monthly evaporation ( $\mathrm{mm}$ ) in experiment $\mathrm{W}$ and (b) the difference subtracting that in experiment $\mathrm{C}$ from experiment $\mathrm{W}$ and of $(\mathrm{c})$ monthly precipitation $(\mathrm{mm})$ in experiment $\mathrm{W}$ and $(\mathrm{d})$ the difference subtracting that in experiment $\mathrm{C}$ from experiment $\mathrm{W}$.
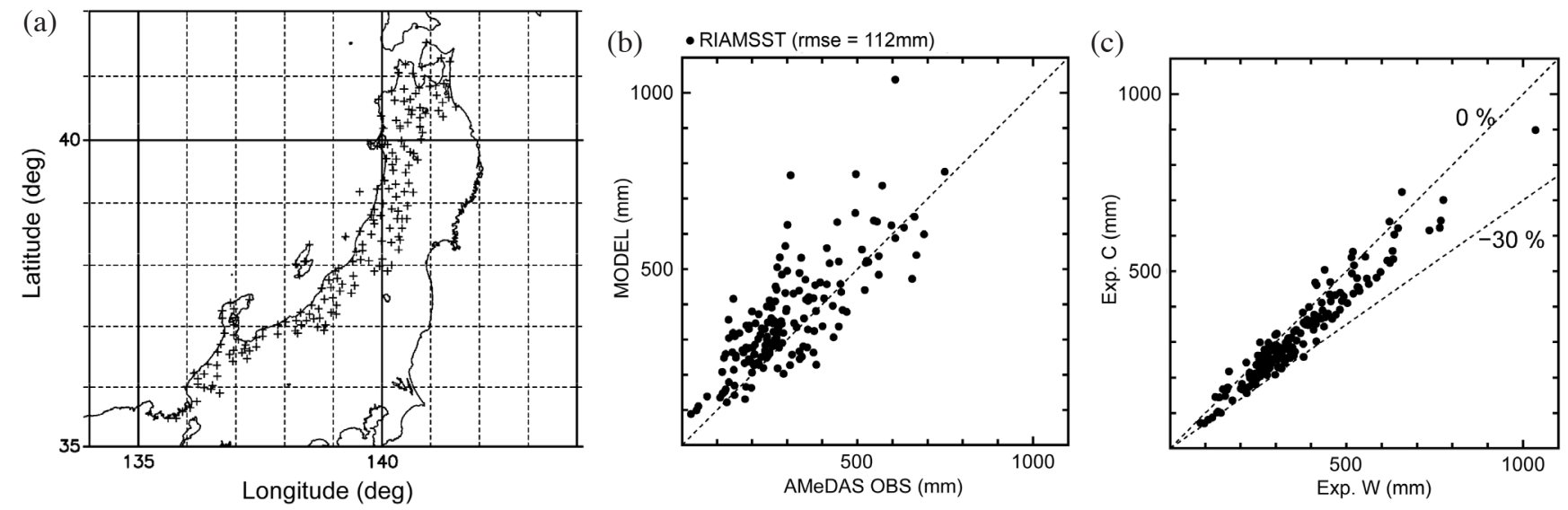

Fig. 10. Locations of (a) AMeDAS sites, and scatter plots of (b) model and observed monthly precipitations and (c) the precipitations in experiments $\mathrm{W}$ and $\mathrm{C}$. The dotted line of $-30 \%$ indicates that the precipitation for experiment $\mathrm{C}$ is $30 \%$ lower than that for experiment $\mathrm{W}$ (is $70 \%$ of that for experiment $\mathrm{W}$ ). 
mesoscale oceanic eddy distribution influences the highresolution SST structure. The difference in the SSTs averaged over the Japan Sea area in 2003 and 2005 leads to the difference of the precipitation averaged over the coastal areas of the Japan Islands, while the SST difference between persistent mesoscale oceanic eddies leads to the local difference of the precipitation in the downstream coastal areas. This indicates that the SST difference between 2003 and 2005 influences the precipitation patterns along the coastal area (Hirose and Fukudome 2006), and the difference of mesoscale oceanic processes between 2003 and 2005 influences the local precipitation distribution. These areaaveraged and eddy-resolving ocean processes are controlled by the Tsushima Warm Current. Thus, the significance of oceanic processes to wintertime precipitation suggests that both monitoring the autumn inlet flow volume through the Tsushima Strait and estimating persistent mesoscale SST structure by an eddy-resolving ocean model can improve the long-term simulations of regional and local patterns in precipitations.

Acknowledgements This study is a part of the project "Monitoring and prediction of marine and atmospheric environmental change in East Asia". We used the AMeDAS (Automated Meteorological Data Acquisition System) data provided by the Japan Meteorological Agency. The NCEP/ GDAS data were sourced from CISL's research data archive (http://dss.ucar.edu/). Weekly NOAA optimum interpolation SST data is provided by the NCEP/NOAA Environmental Modeling Center (http://www.emc.ncep.noaa.gov/ research/cmb/sst analysis/)

\section{REFERENCES}

Chen, S. S., W. Zhao, J. E. Tenerelli, R. H. Evans, and V. Halliwell, 2001: Impact of the AVHRR sea surface temperature on atmospheric forcing in the Japan/East Sea. Geophys. Res. Lett., 28, 4539-4542, doi: 10.1029/ 2001GL013511. [Link]

Deardorff, J. W., 1972: Parameterization of the planetary boundary layer for use in general circulation models. Mon. Weather Rev., 100, 93-106, doi: 10.1175/1520-0 493(1972)100<0093:POTPBL>2.3.CO;2. [Link]

Dudhia, J., 1993: A nonhydrostatic version of the Penn State-NCAR mesoscale model: Validation tests and simulation of an atlantic cyclone and cold front. Mon. Weather Rev., 121, 1493-1513, doi: 10.1175/1520-049 3(1993)121<1493:ANVOTP>2.0.CO;2. [Link]

Dudhia, J., D. Gill, K. Manning, W. Wang, and C. Bruyere, 2005: PSU/NCAR mesoscale modeling system tutorial class notes and users' guide (MM5 modeling system version 3.7). [Link]
Grell, G. A., J. Dudhia, and D. R. Stauffer, 1995: A description of the fifth-generation Penn State/NCAR mesoscale model (MM5), NCAR technical note, NCAR/ TN-398+STR, 122 pp.

Hirose, N. and K. Fukudome, 2006: Monitoring the Tsushima Warm Current improves seasonal prediction of the regional snowfall. SOLA, 2, 61-63, doi: 10.2151/ sola.2006-016. [Link]

Hirose, N., H. Kawanura, H. J. Lee, and J. H. Yoon, 2007: Sequential forecasting of the surface and subsurface conditions in the Japan Sea. J. Oceanogr., 63, 467-481, doi: 10.1007/s10872-007-0042-5. [Link]

Manda, A., N. Hirose, and T. Yanagi, 2005: Feasible method for the assimilation of satellite-derived SST with an ocean circulation model. J. Atmos. Ocean. Technol., 22, 746-756, doi: 10.1175/JTECH1744.1. [Link]

Minobe, S., A. Kuwano-Yoshida, N. Komori, S. P. Xie, and R. J. Small, 2008: Influence of the Gulf Stream on the troposphere. Nature, 452, 206-209, doi: 10.1038/nature06690. [Link]

Morimoto, A. and T. Yanagi, 2001: Variability of sea surface circulation in the Japan Sea. J. Oceanogr., 57, 1-13, doi: 10.1023/A:1011149401735. [Link]

Reynolds, R. W. and T. M. Smith, 1994: Improved global sea surface temperature analyses using optimum interpolation. J. Climate, 7, 929-948, doi: 10.1175/1520-04 42(1994)007<0929:IGSSTA > 2.0.CO;2. [Link]

Takano,Y., Y. Tachibana, and K. Iwamoto, 2008: Influences of large-scale atmospheric circulation and local sea surface temperature on convective activity over the Sea of Japan in December. SOLA, 4, 113-116, doi: 10.2151/sola.2008-029. [Link]

Yamamoto, M. and N. Hirose, 2007: Impact of SST reanalyzed using OGCM on weather simulation: A case of a developing cyclone in the Japan-Sea area. Geophys. Res. Lett., 34, L05808, doi: 10.1029/2006GL028386. [Link]

Yamamoto, M. and N. Hirose, 2008: Influence of assimilated SST on regional atmospheric simulation: A case of a cold-air outbreak over the Japan Sea. Atmos. Sci. Lett., 9, 13-17, doi: 10.1002/asl.164. [Link]

Yamamoto, M. and N. Hirose, 2009: Regional atmospheric simulation of monthly precipitation using high-resolution SST obtained from an ocean assimilation model: Application to the wintertime Japan Sea. Mon. Weather Rev., 137, 2164-2174, doi: 10.1175/2009MWR2488.1. [Link]

Yasuda, T. and K. Hanawa, 1999: Composite analysis of North Pacific subtropical mode water properties with respect to the strength of the wintertime East Asia monsoon. J. Oceanogr., 55, 531-541, doi: 10.1023/A:1007843525069. [Link] 